\title{
Challenges for Landscape Architecture: Designed Urban Ecosystems and Social Acceptance
}

\author{
Emma Salizzoni
}

Citation: Salizzoni, E. Challenges for Landscape Architecture: Designed Urban Ecosystems and Social Acceptance. Sustainability 2021, 13, 3914. https://doi.org/ $10.3390 /$ su13073914

Academic Editor: Fabio Di Carlo

Received: 29 January 2021

Accepted: 24 March 2021

Published: 1 April 2021

Publisher's Note: MDPI stays neutral with regard to jurisdictional claims in published maps and institutional affiliations.

Copyright: (C) 2021 by the author. Licensee MDPI, Basel, Switzerland. This article is an open access article distributed under the terms and conditions of the Creative Commons Attribution (CC BY) license (https:// creativecommons.org/licenses/by/ $4.0 /)$.
Interuniversity Department of Regional and Urban Studies and Planning, Politecnico di Torino, 10125 Torino, Italy; emma.salizzoni@polito.it

\begin{abstract}
The creation of new ecosystems within urban contexts has undeniable benefits for city dwellers in terms of increased urban biodiversity and related provisioning of ecosystem services. However, designing new ecosystems in areas with a high population density or which are subject to intensive use may also generate negative impacts on the anthropic dimension and cause social conflicts that, in turn, can undermine the project's effectiveness. This article focuses on the quite unexplored issue of anthropic "costs" that new urban ecosystems can generate, and on design and management challenges that they open up in terms of social acceptance. Landscape architecture, as a synthesis of ecological, aesthetic, and ethical aspects, seems to be the most appropriate framework for adopting a holistic approach to the design of new urban ecosystems. The article analyzes three Italian landscape architecture projects. All projects adopted spatial measures oriented at fostering perception, understanding, and acceptance of the recreated ecosystems, while preserving them from anthropic impacts. However, these efforts are sometimes jeopardized by a lack of concomitant operational measures, such as stakeholder involvement and site maintenance. Co-existence of delicate habitats and urban functions is thus not utopic but asks that projects effectively integrate ecological sciences, landscape design and management, as well as social-oriented practices.
\end{abstract}

Keywords: landscape architecture; designed ecosystems; urban biodiversity; social acceptance

\section{Introduction}

The multiple benefits that biodiversity in urban areas can deliver are widely acknowledged [1], to the extent that designing for urban biodiversity is becoming an increasingly compelling task [2,3]. Design actions can entail both enhancing the existing biodiversity spaces inside cities and constructing new spaces for biodiversity. This article focuses on this second category of design actions and particularly on those projects that envisage the creation of new ecosystems-namely, "designed ecosystems" [4]—within urban or peri-urban areas.

These projects are aimed at building specific systems of relationships between biotic and abiotic functions capable of hosting certain plant and animal habitats in highly developed contexts and delivering related ecosystem services. However, if anthropic benefits provided by newly recreated urban biodiversity areas are well known and undisputed [5], we cannot forget that, on the other side, the construction of new ecosystems in contexts with a high population density or which are subject to intensive use may also generate negative impacts on the anthropic dimension [6] and cause social conflicts. This is a rather unexplored perspective both at the theoretical and at the practical level. This article would thus like to propose an inversion of the most consolidated points of views by focusing on the anthropic "costs" that the creation of new ecosystems in urban areas can generate and, consequently, on the design and management challenges that they can open up in terms of social acceptance.

The potential of new ecosystem projects to trigger social conflicts is mainly related to certain elements that-allowing for the differences in the various ecosystems that can 
be created (e.g., dunes, lagoons, or forests)—usually characterize this type of design actions. In short: (i) the new area and the related ecosystem functions replace previous, well-established uses and tend to limit the anthropic presence to safeguard the newly recreated habitats; (ii) the new area often re-proposes pre-existing ecosystems that have been completely canceled by the most recent territorial transformation and that local people have never known; (iii) the new area is characterized by strong physical and functional alterity with respect to its context, and this determines a close co-existence of very different functions and spaces.

Conflicts can therefore arise between local population and planners/administrators, first of all in relation to the replacement of deep-rooted practices, as well as to the exclusion of certain players from the transformed territory.

These kinds of conflicts, so-called "conservation conflicts" or "biodiversity conflicts" [7-10], can be exacerbated by the concomitant lack of understanding by the inhabitants of the new area's values. A great part of local population never experienced the pre-existing ecosystems that these kinds of projects usually try to restore, and this can imply a lack of understanding of the related values as well as a poor social support for the projects. This phenomenon, known as "shifting baseline syndrome" [11] (also defined as "generational amnesia" [12,13]), is one of the main threats for the effectiveness of nature conservation policies within cities. According to the "shifting baseline" theory, the environment experienced in life is the baseline for assessing current and future environmental conditions. Therefore, in a context of continuous environmental degradation, there can be increased societal tolerance for landscape quality impoverishment, as well as a change of people's expectations as to what is a desirable state of the natural environment [14], so that new urban ecosystems are not necessarily perceived as an added value. This process is also fueled by the progressive loss of human-nature interactions-the so-called "extinction of experience" [15-17] — that can speed up the loss of memories of earlier environmental states.

Finally, conflicts can also be related to a critical interaction between fauna and humans (similar to the so-called "wildlife conflicts" $[18,19]$ ), caused by the not always intentional introduction of new impacting species $[20,21]$ and, more generally, by the spatial proximity between natural ecosystems and urban spaces and functions.

Ecosystem design must be able to manage or, better yet, prevent these kinds of conflicts. Why do we say "must"? Not only because of a general sense of social sustainability, but also because the other face of conflict, that is, social acceptance, has an evident impact on the project's effectiveness. Social acceptance of the new area is actually the basis for its correct use, contributing to mitigating, from the opposite side, the anthropic impacts on the ecosystem, in a virtuous loop that can sustain a peaceful co-existence between species [22-25].

Awareness of the importance of considering social aspects and implications in the design of new ecosystems, and consequently of adopting a holistic approach that goes beyond the mere parameters of ecological effectiveness and efficiency to embrace the themes of experience and acceptance of the values recreated, is definitely growing, even in the "harshest" sciences of ecological engineering [26,27]. However, this awareness is not yet systematically widespread, neither in scientific studies nor in practice [28]. The intrinsic complexity of landscape architecture discipline-which is increasingly focusing on these kinds of projects-able to synergically address ecological, aesthetic, and ethical aspects $[29,30]$, seems to be the ideal framework for adopting a holistic approach to the creation of new urban ecosystems [31,32] and meet the challenges this poses, also in social terms. In particular, landscape architecture has the potential to strengthen the links existing between "perception", "understanding", and "acceptance" of urban biodiversity values [33-35]. To this aim, it seems crucial that landscape architecture projects for new urban ecosystems work in particular on two main sets of measure, strictly interrelated:

- Spatial measures addressed at (re)including humans within the project area, albeit in a partial and controlled way, to foster human-nature interaction, and, more specifi- 
cally, to favor physical perception and direct experience of the ecosystem functions recreated;

- Operational measures addressed at (i) actively involving the local stakeholders in the design process to foster understanding of the project's objectives, and the values of the new ecosystem, (ii) managing the site to promote its correct use, and (iii) maintaining the landscape to avoid uncontrolled evolutionary processes that could jeopardize a peaceful cohabitation between humans and other species.

This article aims at verifying the application and outcomes of these two sets of measures in landscape architecture projects recently implemented in Italy aimed at constructing new ecosystems in urban and peri-urban settings. This discussion can be of particular value for the Italian context, where the construction of new ecosystems within dense and populated areas is not a common and spread practice yet, compared to the much livelier international context [36].

\section{Materials and Methods}

In order to discuss the abovementioned issues, three Italian landscape architecture projects addressed at designing new ecosystems in urban or peri-urban contexts were selected. Despite the variety of ecosystems recreated-a dune, a wetland, and a forest-all the cases selected present the abovementioned characteristics: (i) replacement of wellestablished uses and limitation of anthropic presence; (ii) recreation of pre-existing-or even historic - ecosystems completely canceled by recent territorial transformation; (iii) formal and functional alterity of the new area with respect to the context and spatial proximity of different spaces and functions. These shared features made it possible to read the three experiences under the common light of the potential or actual social conflicts driven by the project and to detect the spatial and operational measures adopted to address them. Conflicts related to the transformation of places have been prevented in some cases, managed along the way in others, while, in others again, they remain latent and not yet effectively addressed. Thus, even though the cases studies cannot be always considered in every respect as best practices, they can certainly be analyzed as valuable experimental laboratories of landscape design approaches aimed at addressing social conflict issues in the creation of new urban ecosystems.

The reading of case studies is explicitly aimed at highlighting the two abovementioned sets of measures: spatial measures addressed at re-including humans within the project area, such as design of specific routes or recreational areas; and operational measures aimed at the active involvement of the stakeholders, as well as the area's management and the routine maintenance of the site.

The perspective from which cases are analyzed is explicitly that of landscape architecture discipline, so that discussion is more focused on projects' qualitative aspects, than on quantitative issues. The sources used for the case study survey have been mainly bibliographic references, on-site visits, and direct contacts with architects, local authorities, and sites' users. These direct contacts, as well as on-site observations of areas' frequency of use, allowed qualitatively estimating the social acceptance of the new areas. A review of local newspapers gave further support as to the existence, reasons, and nature of possible social conflicts triggered by the projects.

\section{Case Studies}

\subsection{S. Pietro Beach, a New Dune Ecosystem}

The project for the reconstruction of a dune ecosystem along S. Pietro beach in Valledoria (Sassari, Sardinia Region) relates to a coastal context characterized by intensive sea-side tourism. The beach is overlooked by holiday accommodation facilities and a sea-pine forest where the tourist resort of San Pietro a Mare is located.

Before the project, a road, built in the course of the Eighties, ran parallel to the coast, close to the beach, providing direct vehicular access to the shore. The construction of the road, car parks, and the retaining and protecting walls had not only completely erased the 
original dune ecosystem (Figure 1) but had also stiffened the coastal section, encouraging significant erosion processes and an overall retreat of the coastline. In order to address the erosive dynamics as well as environmental and landscape degradation, the municipal administration of Valledoria decided to promote a radical transformation of the local landscape. The project, which was handled by Criteria s.r.l. and by PR.I.MA Ingegneria (2013-2016), covered about $400 \mathrm{~m}$ of coastline and involved the demolition of the road, car parks, and the retaining and protecting walls and the reconstruction and revegetation of the original dune ecosystem. This is a very rare case, along the Italian coast, of restoration of the site's conditions to the status preceding the occurrence of land-taking processes. The intervention also led to a significant change in deep-rooted uses of the coastal area. The direct road access to the seashore was replaced by pedestrian access, with the installation of a walkway which leads tourists from the car park, set back from the beach, toward the coastline.

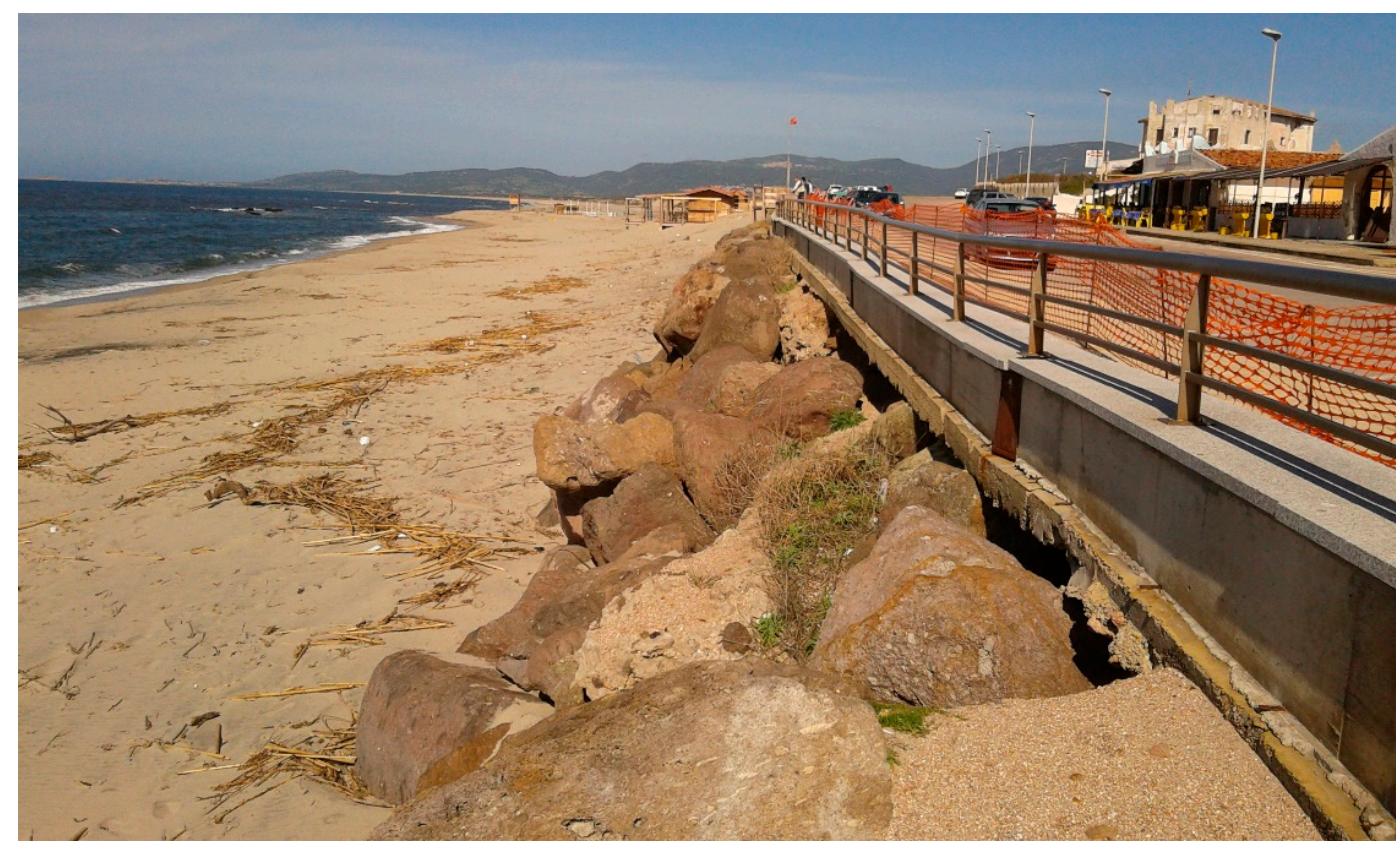

Figure 1. S. Pietro beach before interventions. The road that provided direct vehicular access to the shore had completely erased the original dune ecosystem. Photo courtesy of Maurizio Costa, Criteria s.r.l., 2013.

Even before the project was started, the envisioned elimination of the road had already triggered conflicts between the municipal administration and the users of the beach, who strongly challenged the decision to change well-established practices, such as car access to the sea, and to pedestrianize the coastline. Moreover, further conflicts emerged immediately after the project was implemented, linked to a lack of understanding of the intrinsic dynamism that characterizes any newly restored dune ecosystem, which needs time, between alternating phases of coastal growth and erosion, to achieve a morphosedimentary balance and to reach the desired functional and aesthetic state.

These conflicts were partially fueled by the municipality's failure in implementing policies to actively involve the population and, in particular, processes to raise awareness of the project's features, goals, and expected outcomes. Only weak communicative strategies were envisaged, with the erection of information panels on site a few months before the beginning of the works and the publication of information about the project on the municipality's website. Still, despite these informational gaps and deficiencies, eventually, the project succeeded in addressing conflicts and in fostering the social acceptance of the area thanks to the adoption of specific spatial and operational measures. 
In fact, as far the spatial design of the site is concerned, the project put at the basis of its choices the two-fold objective of protecting from intensive tourism the newly created habitat of the dune, while, at the same time, opening it up to perception by visitors and fostering its appreciation. To this aim, the project entailed the design of a wooden pathway allowing access to the beach that, by respecting the new dune ecosystems (its extrados varies continuously in height to adapt to the dune's morphology), runs continuously along the whole inner edge of the new dune. The pathway is equipped along all its length with seating facing out toward the horizon, allowing visitors to perceive the scenic quality of the recreated dune ecosystem and its biodiversity values (more than 20 native plant species were used). The walkway was thus conceived not only for the functional purpose of distributing flows of users from the backward parking area to the sea, but also as a platform from which to contemplate the new dune ecosystem and, obviously, the sea. No additional physical barriers were installed between the platform and the dunes, since the walkway acts itself as an engine for "positive control" [37] of visitor flows, and the rich dune vegetation discourages people from trampling the recreated ecosystem by acting as a natural barrier (Figure 2).

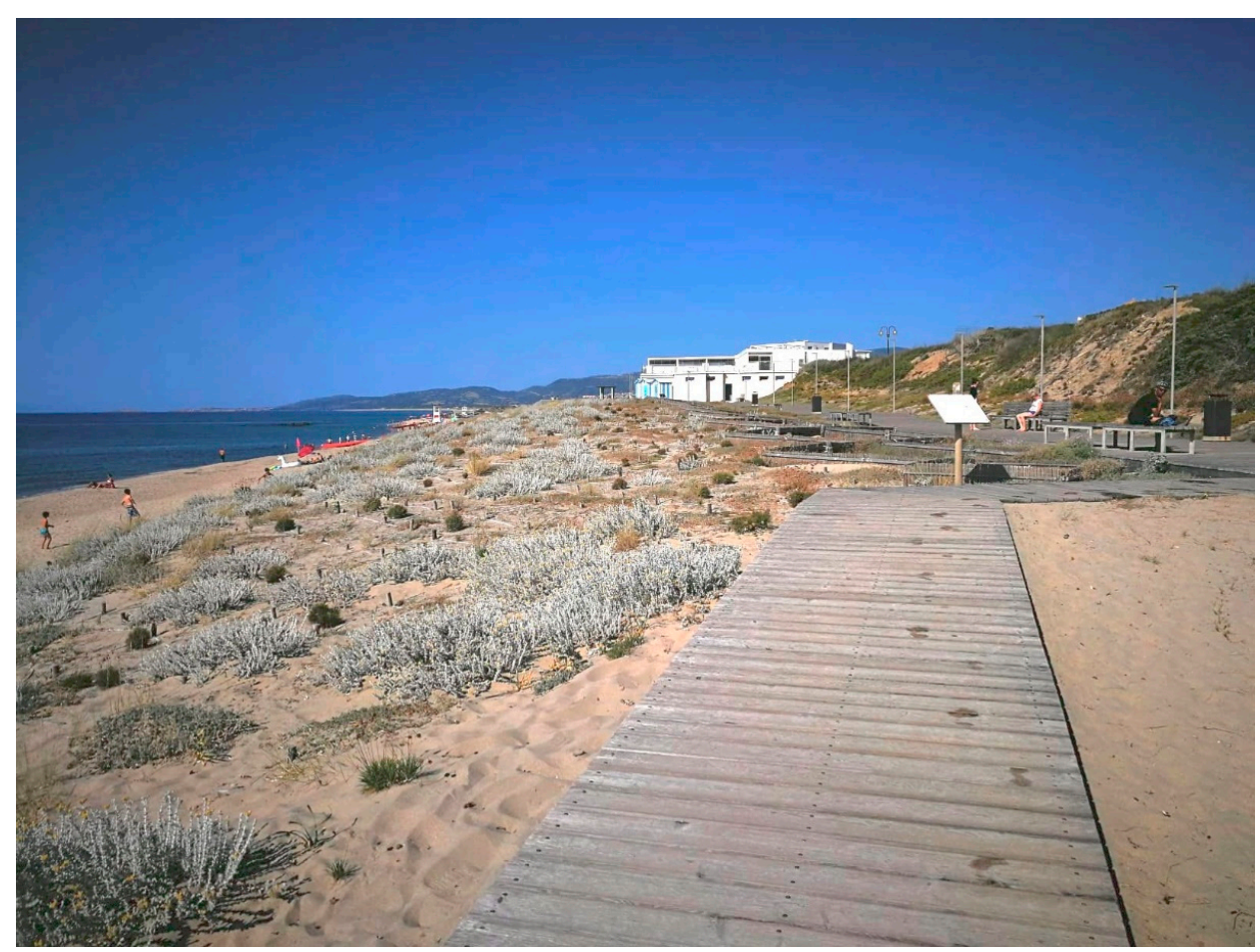

Figure 2. S. Pietro beach after interventions. The walkway and the new dune ecosystem. Photo courtesy of Maurizio Costa, Criteria s.r.l., 2019.

These spatial design choices were supported by a specific management measure adopted to answer social conflicts related to pedestrianization. The project envisaged a sustainable mobility system based on the use of small electric cars capable, if necessary, of carrying users from the car park to the beach. The section of the walkway was thus defined also considering this possibility. The management of this service, initially conceived to be provided by the municipality, was subsequently outsourced to a local cooperative. This quite simple management choice mitigated the total conversion from vehicle to pedestrian use, reducing conflicts without changing the spatial goals of the project.

In the end, the project, despite failing at the beginning in involving local stakeholders, succeeded in addressing the emerging social conflicts thanks to the integration of the abovementioned spatial and management measures. Today, the dune ecosystem has reached its morphosedimentary balance, and the project is greatly valued by residents and tourists who appreciate the improved site's aesthetic quality as well as the greater 
extension of the beach. More intensively used areas now peacefully coexist side by side with the new dune ecosystem. The significant improvement of the local landscape quality has also had positive external effects, triggering processes of regeneration of the private properties in front of it (a hotel and a restaurant).

\subsection{Parco Le Vallette, a Wetland within the City}

Parco Le Vallette in Cerea (Verona, Veneto Region) occupies an area of about 21 hectares surrounded by residential zones and road infrastructure (Figure 3). Before the project, the area was a peri-urban rural landscape resulting from the River Menago reclamation process which took place over the centuries. The intervention (promoted by Cerea municipality and designed by Pippo Gianoni, Dionea SA, and Marco Abordi, Terra s.r.l., 2007-2009) aimed at reconstructing the pre-existing wetland ecosystem in the place of the intensive rural landscape, to improve local biodiversity and landscape quality.

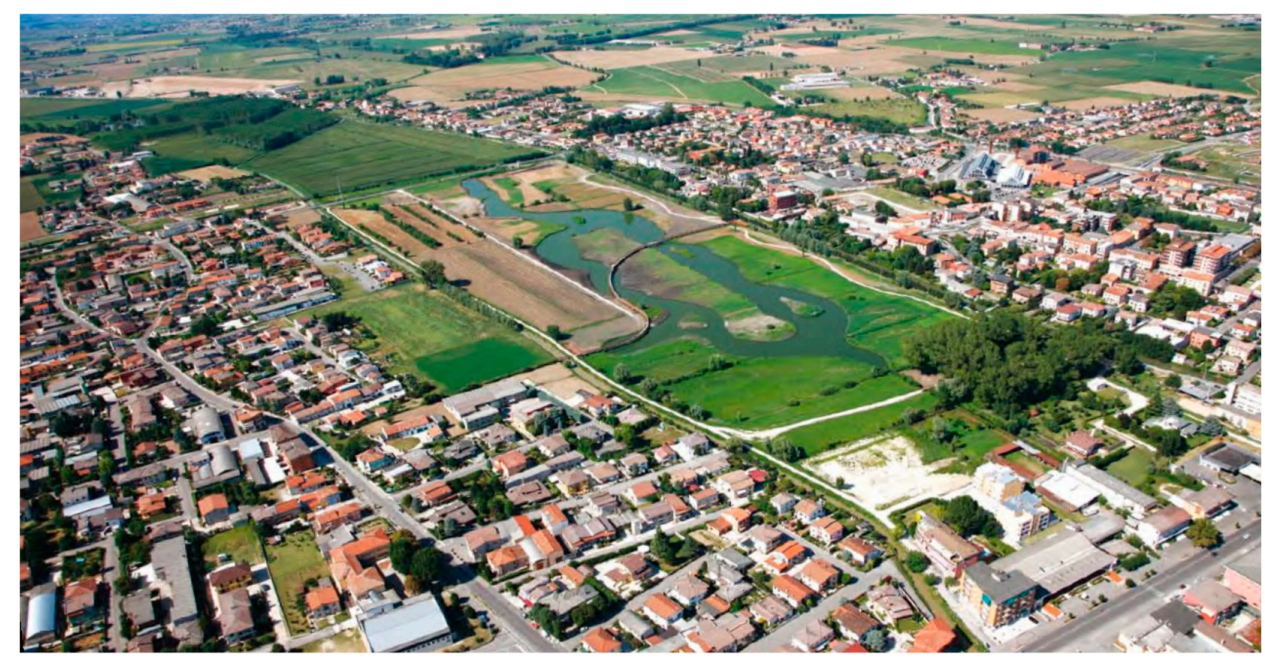

Figure 3. The wetland ecosystem of Parco Le Vallette surrounded by residential areas and road infrastructure. Photo courtesy of T.E.R.R.A. s.r.l. and Consorzio di Bonifica Veronese, 2009.

Unlike the case of S. Pietro beach, Cerea municipality decided to actively involve local inhabitants in the project right from the initial phases. During the first public meeting (2005), two alternative design scenarios were presented and discussed with residents: one involving the creation of a green area for recreational purposes with a road linking the two parts of the town located east and west of the site, and the other involving the recreation of the historic wetland ecosystem, with exclusively pedestrian links between the two surrounding urban areas. The choice of this second option, approved extensively by local inhabitants, who also provided design suggestions, allowed the municipality to implement the project with a strong social support, avoiding social conflicts. The final plan was presented to the townspeople a year later (2006) before works started. Other communication strategies-such as the opening of the building site to allow residents to check the progress of the works-further supported the process of social acceptance. Moreover, ecological impact assessments carried out before the intervention, along with the implementation of specific technical measures during the execution of the works, prevented and mitigated potential conflicts related to the presence of mosquitos.

These operational measures were accompanied by spatial design choices aimed at fostering, as much as possible, interaction between visitors and the new ecosystems. The project involved the creation of a wetland of about 40,000 sqm. A main island was created in a barycentric position with respect to the wetland, surrounded by some smaller secondary islands. The islands are privileged sites for the nesting of birds and are characterized by marsh vegetation so that they can act as wildlife refuge. To protect the new habitats, the islands are physically inaccessible. However, the presence of accessible meadows that in 
several points stretch out to the waters allows visitors to establish a direct relationship with the wetland and a visual connection with the islands and the wildlife that lives on them. Moreover, a raised cycle-pedestrian path made of wood and steel and running for a distance of about $500 \mathrm{~m}$ was set up, connecting the two parts of the town. The path winds its way through the central wetland, approaching the smaller islands and passing through the main one, but without allowing access to it. Crossing the walkway, it is possible to visually appreciate the wetland as a whole without interfering with the delicate habitats (Figures 4 and 5).

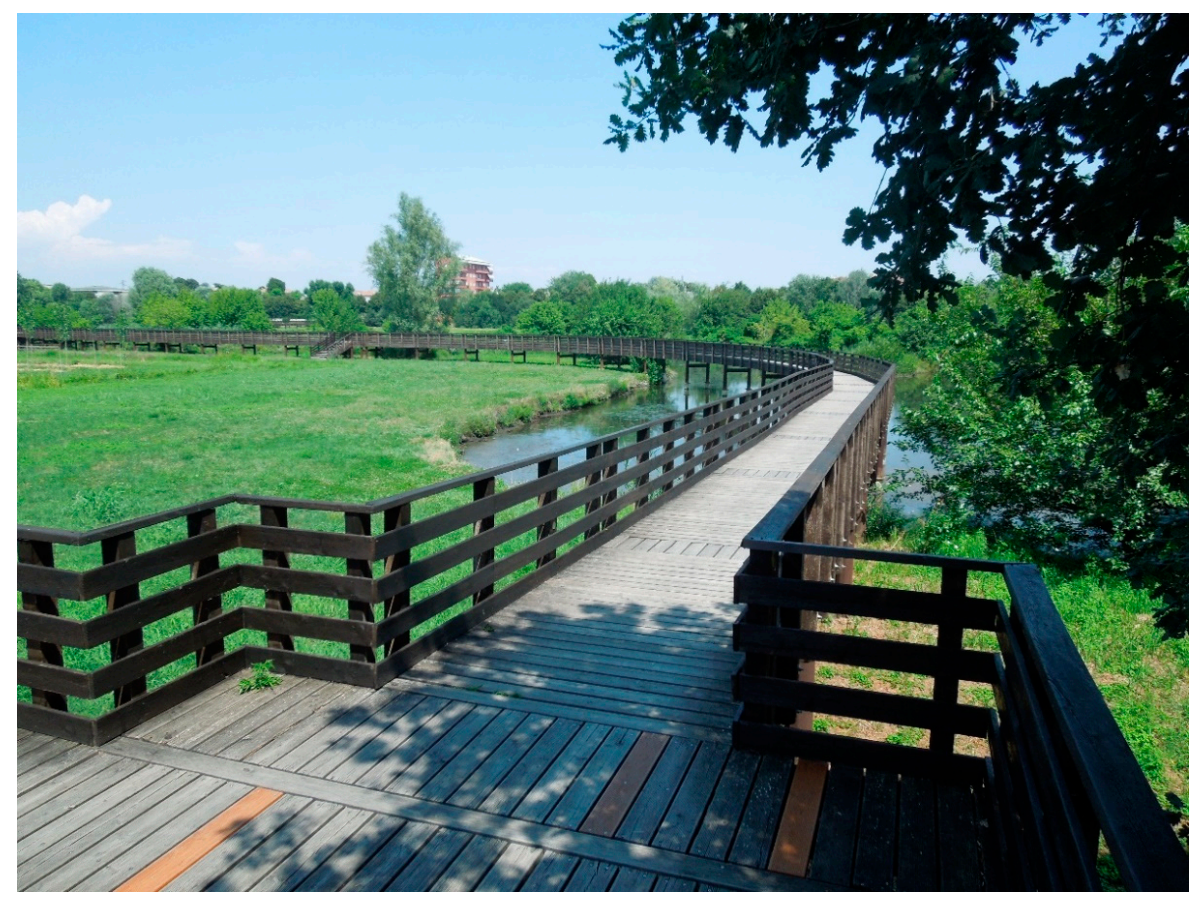

Figure 4. The walkway winding through the Parco Le Vallette wetland. Photo Emma Salizzoni, 2020.

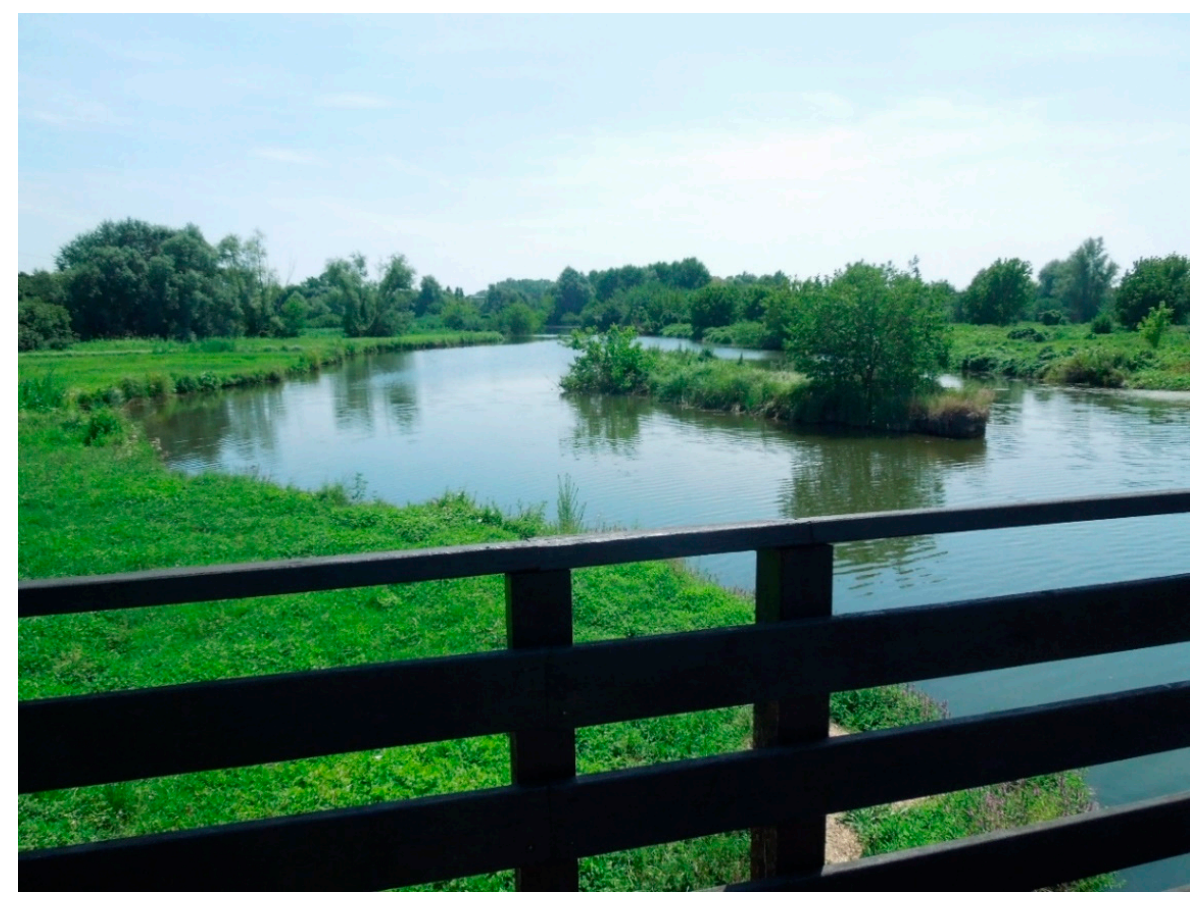

Figure 5. The walkway approaches the smaller islands without interfering with the newly recreated habitats in Parco Le Vallette. Photo Emma Salizzoni, 2020. 
Today, the area is used daily by pedestrians and cyclists. At the same time, it is home to a rich biodiversity of plants and is populated by a variety of animal species. Any conflicts which might have been generated by the drastic landscape transformation, limitation of uses, and the presence of species such as mosquitoes were prevented thanks to the actions undertaken. The overall social acceptance of the area has even generated a virtuous process of voluntary maintenance of the site on behalf of city inhabitants.

\subsection{Bosco Querini, a Peri-Urban Woodland Ecosystem}

The Bosco di Mestre project ("Mestre Woodland") in Mestre (Venice, Veneto Region) is an even different case in terms of social participation, compared to the previous ones. In this case, the local people were not just involved in the project, but they acted as the driving force itself behind it. In 1984, local ecological movements strongly protested against the construction of a new hospital structure in the place of one of the last strips of original lowland woodland existing at the time. In the wake of these civil protests, from the early 1990s (1994), the City of Venice, with the Veneto Regional Forest Agency, began a huge process of re-forestation of Mestre peri-urban areas, with the aim of restoring the historic woodland canceled by intense land consumption (urban sprawl) and agricultural overexploitation (intensive farming).

The overall process was thus supported by Mestre inhabitants, who were aware of re-forestation benefits $[38,39]$ and looked at the project as a precious opportunity for periurban landscape improvement. Unlike city inhabitants, however, farmers struggled-as they continue to struggle-to accept the insertion of a forest ecosystem within the rural landscape. Beyond a general hostility towards innovations, this was mainly due to the several impacts that they assumed such an insertion might have on the adjacent fields (e.g., presence of wild animals, or projection of tree shadow on the fields).

To date, the forestation process has entailed the creation of about 230 hectares of new forest ecosystems (lowland mixed oak and hornbeam woods) that have mainly replaced peri-urban intensive rural areas owned or rented by the municipality. The Venice Urban Development Plan also envisaged the possibility for farmers, sustained by specific incentives, to convert rural land in forest ecosystems, but to date no private rural area has been transformed yet, a circumstance which confirms that project's acceptance on behalf of farmers continues to be moderate.

The ultimate aim of the Bosco di Mestre-that is managed by the Istituzione Bosco e Grandi Parchi of the municipality of Venice-was to significantly improve local ecological quality and biodiversity, while opening the new forest ecosystem to potential users in order to spread the awareness of its value and to foster social acceptance [40]. Thus, the search for a delicate balance between protecting the new habitats and encouraging people to visit them was at the heart of this forward-looking project from its outset. To this aim, the project entailed specific spatial and operational choices, tightly related.

An effective example is given by Bosco Querini ("Querini Woodland", around 200 ha). This is the biggest and most recent woodland reconstructed within the Bosco di Mestre project. It is surrounded by an intensive agricultural landscape and scattered settlements. The woodland encompasses an articulated network of cycle, bridle, and pedestrian paths that cross the site to allow the discovery of the new forest ecosystem, as well as some open areas (meadows) dedicated to recreational activities. The insertion of explanatory panels along the pathways fosters communication of the new ecosystem's values, with educational ambitions.

Parallelly, the Management Plan (2014) provides a wide variety of forest management interventions to encourage different woodland perceptual experiences by visitors: more sparse wooded areas with a substantial absence of shrubby undergrowth and permeable to the eye are expected to delimit the paths and recreational meadows, creating a context that is not only aesthetically but also psychologically pleasing for visitors in terms of perceived safety; by contrast, in most peripheral areas, a denser, not visually permeable, 
and irregular woodland is envisaged to discourage accessibility and host most delicate habitats (Figure 6).

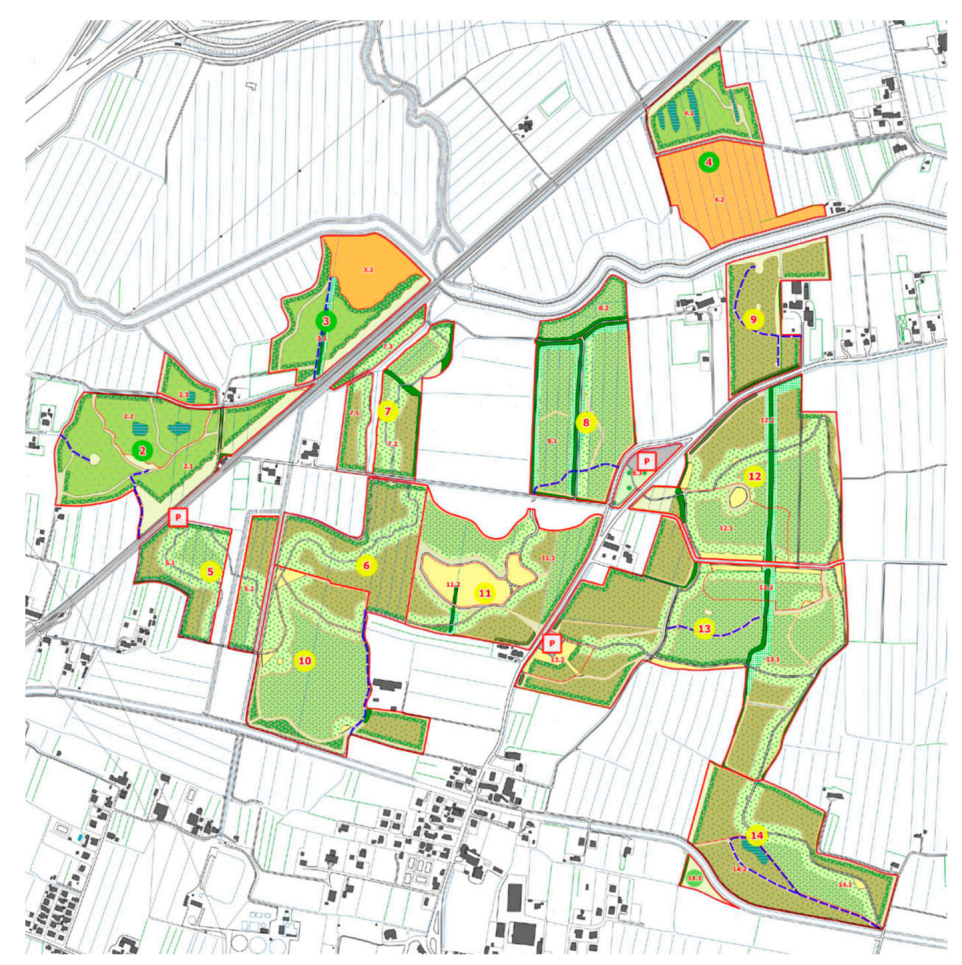

Figure 6. The Bosco Querini Management Plan (excerpt from Piano di Gestione del Bosco di MestreCarta degli Interventi, 2014, original scale 1:5,000): in lighter green, the sparse and visually permeable wooded areas that delimit the paths and meadows (highlighted in yellow) within the forest; in darker green, denser wooded areas, but still permeable to the eye; in brown, irregular and not permeable wooded areas that host the most delicate and inaccessible habitats (orange areas are dedicated to further woodland developments). Image courtesy of Istituzione Bosco e Grandi Parchi, Comune di Venezia.

Unfortunately, in recent years, this alternance between more and less dense forest areas to mark the difference between inaccessible and accessible zones has been partially altered by the poor implementation of the guidelines set out in the Management Plan. Due to a lack of financial resources, forest clearing could not be regularly implemented. As a consequence, today a very dense vegetation "besieges" the pathways, and the undergrowth is not always visible (Figure 7). This poor site maintenance risks not only compromising the ecological quality of the site, but also feeding a feeling of insecurity in visitors, transforming the perception and acceptance of the new forest landscape into hostility. Moreover, an uncontrolled rewilding process could trigger critical interactions between wild animals and the surrounding agricultural fields (Figure 8), fueling social conflicts with farmers, who have less enthusiastically supported the Bosco di Mestre project, compared to city inhabitants. 


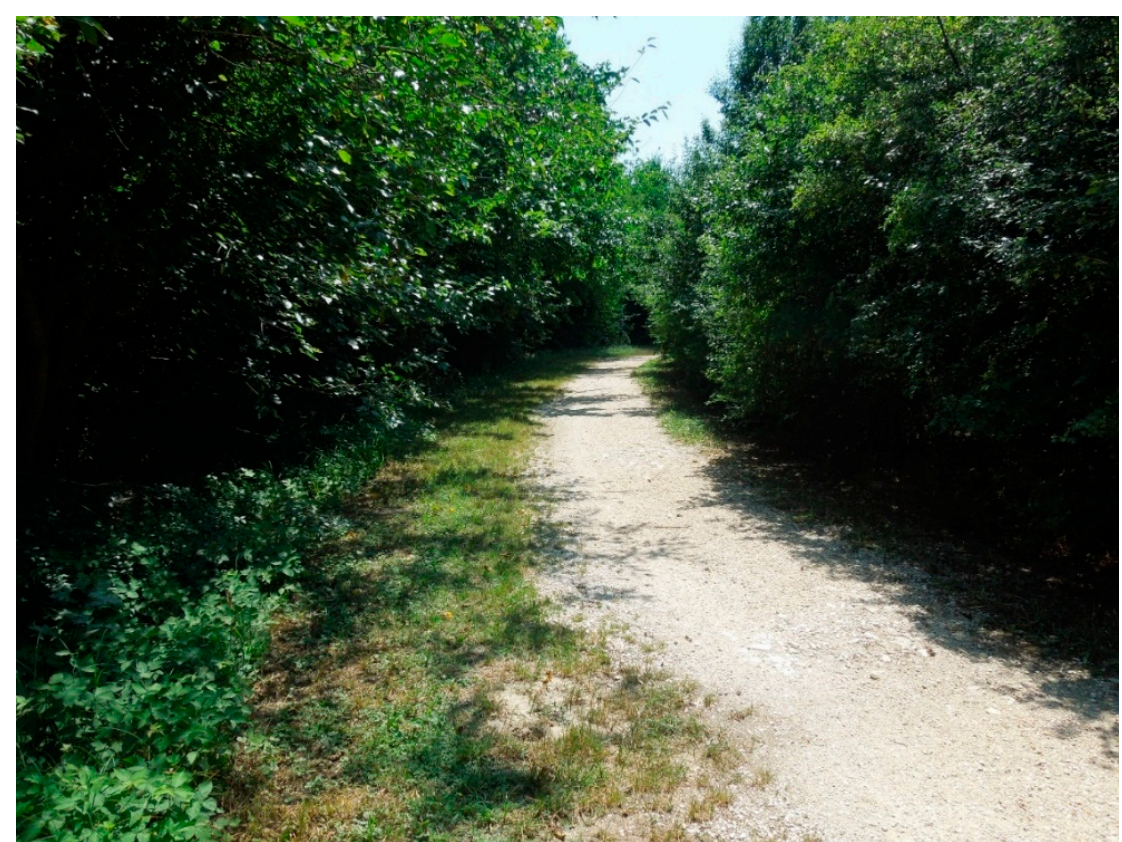

Figure 7. A pathway crossing Bosco Querini. Photo Emma Salizzoni, 2020.

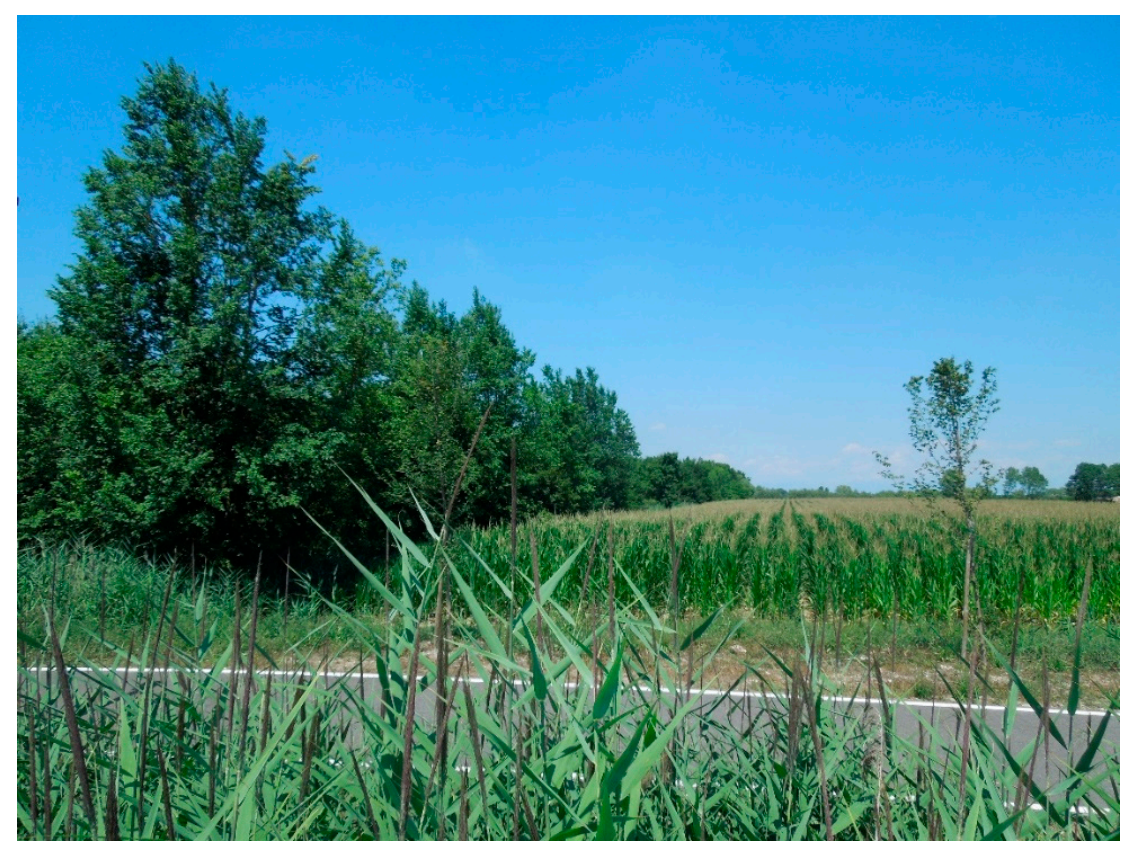

Figure 8. The close spatial interaction between Bosco Querini and the rural landscape. Photo Emma Salizzoni, 2020.

\section{Discussion and Concluding Remarks}

The landscape architecture projects discussed above represent quite rare cases, in Italy, of design of new ecosystems in highly developed areas. In their efforts to address social aspects connected to ecosystem creation, they reveal lots of lights, but some shades too. The most challenging area of action seems to be that related to operational measures, such as active involvement of local stakeholders, as well as the area's management and its routine maintenance.

As far as active involvement of local stakeholders is concerned, case studies show how the development of communication activities, awareness raising, and involvement of residents in the project's choices are crucial to favor the acceptance of the new area. 
Additionally, due to the mentioned "shifting baseline syndrome" [14], the re-creation of pre-existing or even historical ecosystems is not necessarily always seen as an added value by the public, especially if promoted by "expert" visions. In the case of S. Pietro beach, the main driver behind the demand for dune ecosystem restoration was the municipality's intention to stop the intensive coastal erosion processes and to improve environmental and landscape quality. This intention was not adequately shared with local inhabitants, who had become accustomed to the artificial coastal landscape and considered car access to the sea a priority. The lack of a participatory approach entailed a very late acceptance by residents of the new landscape, eventually attained by way of specific management choices as well as by an "inclusive" spatial design of the area. By contrast, in Parco Le Vallette, even if the driver for the reconstruction of the wetland historical ecosystem was again the municipality's intention to improve environmental and landscape quality, a careful process of awareness raising about the importance of pursuing this objective was put in place, and the project was capable of gaining strong social support from its very inception. Finally, in Bosco Querini, the first driver for the forest historical ecosystem reconstruction was the local population itself, mainly Mestre citizens, and this certainly facilitated the overall project's implementation. However, a classic conflict between "town" and "country" visions emerged [41], to the extent that farmers never strongly supported the project, and this fact is still today an open issue.

Certainly, participatory strategies require effort and timing that are by no means ordinary for a local administration. These strategies, however, are rewarding not only because, as mentioned above, a project's social acceptance is the basis for the new area's correct use and species co-existence, but also because it can generate valuable externalities. This is the case of Parco Le Vallette (Cerea), where site maintenance actions today are carried out also on a voluntary basis by local residents.

Indeed, the routine maintenance of the new areas is another crucial factor. This is true for all landscape architecture projects, but even more so for new ecosystem projects. Routine maintenance is firstly needed for ecological reasons: "designed ecosystems", though they can be designed for self-sustainability, more often require ongoing maintenance to achieve their goals [4]. Moreover, maintenance is key in projects explicitly aimed at increasing biodiversity, since rewilding is not necessarily synonymous with augmented biodiversity [42]. However, routine maintenance is also needed to foster a harmonious and non-conflictual humane-nature interaction and promote new ecosystem social acceptance. Uncontrolled nature evolutionary processes can result in the significant alteration of the initial spatial choices, as happened in the case of Bosco Querini (Mestre). Long-term funding, not limited to the ecosystem's construction phase, is fundamental to sustain these maintenance activities, constituting one of the main current challenges in the "placekeeping" of public spaces [43].

As far as spatial measures are concerned, we can note that all projects work for (re)including the human component in the sites, in order to allow their use and exploration and to prevent potential conflicts deriving from a radical exclusion of anthropic presence. This inclusion, however, is carefully controlled to allow the undisturbed development of habitats and avoid the alteration of the newly recreated biodiversity values. To prevent accessibility to most vulnerable areas, projects do not use negative control systems, such as fence or prohibitive signs [37], but exploit the "barrier" characteristics of the ecosystems themselves: the thickly revegetated dune in S. Pietro beach, the water around the main island in Parco Le Vallette, the densest woodland areas in Bosco Querini. At the same time, the design of pathways and recreational areas supports visitors in establishing a visual connection with the newly recreated habitats, which are made available for perception to guarantee biodiversity values' understanding and their social acceptance. In some cases, this process is also strengthened by the insertion of informative panels, promoting a more aware observation of ecosystem values.

Thus, these projects work on functionally separating, but visually connecting humans and the most fragile habitats, resulting in complex as well as harmonious landscapes where 
inaccessible and high-biodiversity areas coexist side by side with accessible and more intensively used areas. Thanks to this careful design approach, visitors do not feel excluded from the site, but a part of it. Contemplating nature at a distance can even strengthen the understanding of other species [44], promoting a step beyond acceptance, that is, the assumption of responsibility toward plant and animal biodiversity.

Looking at the three discussed cases, it is clear that both spatial and operational measures are needed to address social challenges posed by the creation of new urban ecosystems. Since these two spheres of action and their outcomes are strictly interrelated, they should be conceived of as integrated parts of a unitary design process [43,45]. This vision is in accordance with the concept of a landscape architecture project which cannot be reduced to the construction of a site, but which stretches over time, before and after that site's creation, and which considers participatory strategies and site "care" to be crucial components of the design effort. The goal of a co-existence between delicate habitats and urban functions is thus certainly not utopic but, perhaps more than other types of landscape architecture projects, demands a holistic approach that effectively links ecological sciences, landscape design and management, as well as social-oriented practices.

Funding: This research received no external funding.

Conflicts of Interest: The author declares no conflict of interest.

\section{References}

1. Miller, J.R. Conserving biodiversity in metropolitan landscapes. A matter of scale (but which scale?). Landsc. J. 2008, 27, 114-126. [CrossRef]

2. Müller, N.; Ignatieva, M.; Nilon, C.H.; Werner, P.; Zipperer, W.C. Patterns and trends in urban biodiversity and landscape design. In Urbanization, Biodiversity and Ecosystem Services: Challenges and Opportunities a Global Assessment; Elmqvist, T., Fragkias, M., Goodness, J., Güneralp, B., Marcotullio, P.J., McDonald, R.I., Parnell, S., Schewenius, M., Sendstad, M., Seto, K.C., et al., Eds.; Springer: Dordrecht, The Netherlands, 2013; pp. 123-174.

3. Shwartz, A. Designing nature in cities to safeguard meaningful experiences of biodiversity in an urbanizing world. In Urban Biodiversity. FROM Research to practice; Ossola, A., Niemelä, J., Eds.; Abingdon: Routledge, UK, 2018; pp. $200-215$.

4. Higgs, E. Novel and designed ecosystems. Restor. Ecol. 2017, 25, 8-13. [CrossRef]

5. Zari, M.P. The importance of urban biodiversity-An ecosystem services approach. Biodivers. Int. J. 2018, 2, 357-360. [CrossRef]

6. Buckley, M.C.; Crone, E.E. Negative Off-Site Impacts of Ecological Restoration: Understanding and Addressing the Conflict. Conserv. Biol. 2008, 22, 1118-1124. [CrossRef] [PubMed]

7. Gutiérrez, R.J.; Wood, K.A.; Redpath, S.M.; Young, J.C. Conservation Conflicts: Future Research Challenges. In Current Trends in Wildlife Research; Mateo, R.M., Arroyo, B., Garcia, J.T., Eds.; Springer: Dordrecht, The Netherlands, 2016; pp. $267-282$.

8. Marshall, K.; White, R.; Fischer, A. Conflicts between humans over wildlife management: On the diversity of stakeholder attitudes and implications for conflict management. Biodivers Conserv. 2007, 16, 3129-3146. [CrossRef]

9. White, R.M.; Fischer, A.; Marshall, K.; Travis, J.M.J.; Webb, T.J.; di Falco, S.; Redpathf, S.M.; van der Wal, R. Developing an integrated conceptual framework to understand biodiversity conflicts. Land Use Policy 2009, 26, 242-253. [CrossRef]

10. Lecuyer, L.; White, R.M.; Schmook, B.; Calmé, S. Building on common ground to address biodiversity conflicts and foster collaboration in environmental management. J. Environ. Manag. 2018, 220, 217-226. [CrossRef]

11. Pauly, D. Anecdotes and the shifting baseline syndrome of fisheries. Trends Ecol. Evol. 1995, 10, 430. [CrossRef]

12. Kahn, P.H., Jr. Children's Affiliations with Nature: Structure, Development, and the Problem of Environmental Generational Amnesia. In Children and Nature: Psychological, Socio-cultural, and Evolutionary Investigations; Kahn, P.H., Jr., Kellert, S.R., Eds.; MIT: Cambridge, UK, 2002; pp. 93-116.

13. Kahn, P.H., Jr.; Friedman, B. Environmental Views and Values of Children in an Inner-City Black Community. Child Dev. 1995, 66, 1403-1417. [CrossRef]

14. Soga, M.; Gaston, K.J. Shifting baseline syndrome: Causes, consequences, and implications. Front. Ecol. Environ. 2018, 16, 222-230. [CrossRef]

15. Pyle, R.M. The extinction of experience. Horticulture 1978, 56, 64-67.

16. Soga, M.; Yamaura, Y.; Aiko, T.; Shoji, Y.; Kubod, T.; Gaston, K.J. Reducing the extinction of experience: Association between urban form and recreational use of public greenspace. Landsc. Urban Plan. 2015, 143, 69-75. [CrossRef]

17. Soga, M.; Gaston, K.J. Extinction of experience: The loss of human-nature interactions. Front. Ecol. Environ. 2016, 14, 94-101. [CrossRef]

18. Conover, M. Resolving Human-Wildlife Conflicts, the Science of Wildlife Damage Management; Lewis Publishers CAC Press: Boca Raton, FL, USA, 2002. 
19. Graham, K.; Beckerman, A.P.; Thirgood, S. Human-predator-prey conflicts ecological correlates, prey losses and patterns of management. Biol. Conserv. 2005, 122, 159-171. [CrossRef]

20. Finlayson, C.M.; Horwitz, P. Wetlands as Settings for Human Health-the Benefits and the Paradox. In Wetlands and Human Health; Finlayson, C.M., Horwitz, P., Weinstein, P., Eds.; Springer: Dordrecht, The Netherlands, 2015; pp. 1-13.

21. Hanford, J.K.; Webb, C.E.; Hochuli, D.F. Management of urban wetlands for conservation can reduce aquatic biodiversity and increase mosquito risk. Appl Ecol. 2020, 57, 794-805. [CrossRef]

22. Steffen, W.; Crutzen, P.J.; Mcneill, J. The Anthropocene: Are Humans Now Overwhelming the Great Forces of Nature? AMBIO 2007, 36, 614-621. [CrossRef]

23. Prominski, M. Come together. Enhancing biodiversity in high-density cities by giving space to humans and non-humans. In Urban Landscapes in High-Density Cities: Parks, Streetscapes, Ecosystems; Rinaldi, B.M., Tan, P.Y., Eds.; Birkhäuser: Basel, Switzerland, 2019; pp. 190-203.

24. Prominsky, M. Andscapes: Concepts of nature and culture for landscape architecture in the 'Anthropocene'. J. Landsc. Archit. 2014, 9, 6-19. [CrossRef]

25. Caravaggi, L.; Imbroglini, C.; Lei, A. Progetto di paesaggio e interazione con le altre specie viventi. Ri-Vista. Ric. Per La Progett. Del Paesaggio 2020, 1, 18-37.

26. Higgs, E. What is Good Ecological Restoration? Conserv. Biol. 1997, 11, 338-348. [CrossRef]

27. Fernández-Manjarrés, J.F.; Roturier, S.; Bilhaut, A. The emergence of the social-ecological restoration concept. Restor. Ecol. 2018, 26, 404-410. [CrossRef]

28. Hychka, K.; Gottschalk Druschke, C. Adaptive Management of Urban Ecosystem Restoration: Learning From Restoration Managers in Rhode Island, USA. Soc. Nat. Resour. 2017, 30, 1358. [CrossRef] [PubMed]

29. Musacchio, L.R. Metropolitan landscape ecology using translational research to increase sustainability, resilience, and regeneration. Landsc. J. 2008, 27, 1-8. [CrossRef]

30. Zeunert, J. Landscape Architecture and Environmental Sustainability: Creating Positive Change through Design; Bloomsbury: London, UK, 2017.

31. Grose, M.; Frisby, M. Mixing ecological science into landscape architecture. Front. Ecol. Environ. 2019, 17, 296-297. [CrossRef]

32. Sack, C. Landscape architecture and novel ecosystems: Ecological restoration in an expanded field. Ecol. Process. 2013, 2, 1-9. [CrossRef]

33. Nassauer, J.I. Messy ecosystems, orderly frames. Landsc. J. 1995, 14, 161-170. [CrossRef]

34. Nassauer, J.I. Placing Nature. Culture and Landscape Ecology; Island Press: Covelo, CA, USA, 1997.

35. Botzat, A.; Fischer, L.K.; Kowarik, I. Unexploited opportunities in understanding liveable and biodiverse cities. A review on urban biodiversity perception and valuation. Glob. Environ. Chang. 2016, 39, 220-233. [CrossRef]

36. Rinaldi, B.M. Welcome to the City of the Future. Where Everything Begins with a Park. In Urban Landscapes in High-Density Cities: Parks, Streetscapes, Ecosystems; Rinaldi, B.M., Tan, P.Y., Eds.; Birkhäuser: Basel, Switzerland, 2019; pp. 117-139.

37. Loidl, H.; Bernard, S. Opening Spaces. Design as Landscape Architecture; Birkhäuser: Basel, Switzerland, 2003.

38. Tempesta, T. Il valore paesaggistico-ambientale degli interventi di riforestazione della pianura Veneta: Il caso del bosco di Mestre (VE). In Percezione e Valore del Paesaggio; Tempesta, T., Thiene, M., Eds.; Franco Angeli: Milano, Italy, 2006; pp. $189-208$.

39. Vecchiato, D.; Tempesta, T. Valuing the benefits of an afforestation project in a periurban area with choice experiments. Forest Policy Econom. 2013, 26, 111-120. [CrossRef]

40. Zanetti, M. Considerazioni sulla fruizione. In Il Bosco di Mestre; Zanetti, M., Ed.; Nuovadimensione: Portogruaro, Italy, 2007; pp. $75-80$.

41. Conan, M. L'invention des identités perdues, In Cinq Propositions Pour Une Théorie de Paysage; Berque, A., Ed.; Champ vallon: Seyssel, France, 1994; pp. 33-49.

42. Kowarik, I.; Langen, A. Natur-Park Südgelände: Linking Conservation and Recreation in an Abandoned Railyard in Berlin. In Wild Urban Woodlands; Kowarik, I., Körner, S., Eds.; Springer: Berlin/Heidelberg, Germany, 2005; pp. $287-299$.

43. Dempsey, N.; Burton, M. Defining place-keeping: The long-term management of public spaces. Urban For. Urban Green. 2012, 11, 11-20. [CrossRef]

44. De Block, G.; Vicenzotti, V. The effect of affect. A plea for distance between the human and non-human. JoLA-J. Landsc. Archit. 2018, 13, 46-55. [CrossRef]

45. Salizzoni, E.; Pérez-Campaña, R. Design for biodiverse urban landscapes: Connecting place-making to place-keeping. Ri-Vista. Ricerche per la progettazione del paesaggio 2019, 2, 130-149. 